\title{
Estudo, características Post mortem e possíveis medidas de prevenção na ocorrência dos casos de amiloidose hepática em equinos utilizados para produção de soros hiperimune
}

\author{
[Study, prevention, and post mortem characteristics of the occurrence of hepatic amyloidosis in \\ horses used for the production of hyperimmune sera]
}

\section{"Relato de Caso/Case Report"}

\author{
Renan Guilherme Mota ${ }^{1 *}$, Eudes Esteves do Nascimento ${ }^{1}$
}

${ }^{1}$ Universidade Estadual de Londrina, Londrina-PR, Brasil.

*Autor para correspondência/Corresponding author: E-mail: renangmota18@gmail.com

\begin{abstract}
Resumo
A produção de soros hiperimunes compõe parte fundamental no combate e tratamento à doenças causadas por toxinas e venenos produzidos por vírus, bactérias ou animais peçonhentos. Geralmente utiliza-se a espécie equina (Equus caballos) pela docilidade e alta capacidade de produção de soro. Dentro da rotina produtiva existem fatores de nutrição e manejo que quando somados à alta estimulação antigênica podem levar à ocorrência de quadros de amiloidose. O caso relatado descreve os sinais post-mortem encontrados em um equino macho, adulto, e com causa-mortis vinculada à ruptura de lobos hepáticos acometidos pela deposição amiloide, promovendo hemorragia intra-abdominal. Foram adotadas algumas medidas relacionadas a dieta e manejo dos animais dentro da propriedade, almejando auxiliar na manutenção e avaliação da saúde, recuperação física e hematológica pós-sangria e até mesmo no rendimento e controle da produção de anticorpos por $\mathrm{mL}$ de soro. Os quadros relacionados à amiloidose são raros e normalmente sem a presença de sinais clínicos, sendo a monitoração frequente para detecção precoce de problemas e avaliação da saúde, uma boa alternativa para controle da produção e do bem-estar animal.
\end{abstract}

Palavras-chave: equinos; hiperimunização; imunologia; lesão hepática; resposta imune.

\begin{abstract}
The production of hyperimmune serum is a fundamental step in the combat and treatment of diseases caused by toxins and poisons made by virus, bacteria, or venomous animals. Usually, the species used in this activity is equine (Equus caballos) due to the docility and high capacity of serum production. Inside a productive routine there are factors of nutrition and handling that, when added to the great and frequent antigenic stimulation of horses can lead to the occurrence of amyloidosis. The reported case describes the post-mortem signs found in a male equine, adult, and with cause of death associated with the rupture of hepatic lobes affected by the amyloid deposition, promoting intra-abdominal bleeding. Some measures related to diet and animal management were adopted, aiming to assist in the maintenance and evaluation of health, physical, and hematological recovery after bleeding and even in the yield and control of the production of antibodies per $\mathrm{mL}$ of serum. Presentations related to amyloidosis are rare and usually without symptoms, with frequent monitoring for early detection of problems and health assessment, a good alternative for controlling production and animal welfare.
\end{abstract}

Keywords: horses; hyperimmunization; imune response; immunology; liver injury.

\section{Introdução}

A utilização de soros hiperimunes atualmente é essencial para o tratamento de intoxicações e toxinfecções em animais e humanos. Essa responsabilidade leva a necessidade de fluxo produtivo constante, do contrário gera prejuízos à própria saúde pública. O mecanismo básico de ação no emprego dos soros consiste no fornecimento de

anticorpos aptos a atuar no organismo dos indivíduos acometidos, antagonizando ou inativando a ação da substância indesejada, com o objetivo de ao menos minimizar os efeitos nocivos em exposições recentes (Parra et al., 2009). De acordo com dados publicados pelo Instituto Butantan (2017), centro de referência nacional e 
internacional de produção de soros, hoje são produzidos cerca de 13 tipos de soros no Brasil, seja contra venenos de animais peçonhentos, ou toxinas e antitoxinas de vírus e bactérias. Para tal fim, opta-se pelo uso da espécie equina devido ao volume de sangue possível de ser manipulado, características imunológicas e de reposta humoral, temperamento e facilidade de manejo (Betiol et al., 2008).

Para produção de soros hiperimunes, buscase uma concentração satisfatória mínima de anticorpos por $\mathrm{mL}$ de sangue, oriunda da eficiência na resposta imunológica individual de cada equino. Para atingir bons níveis produtivos seguem-se protocolos próprios padronizados para indução da produção da resposta imunológica e posterior coleta dos anticorpos. Em geral os antígenos específicos são adquiridos por produção própria ou por formulações comerciais, sendo transformados em soluções de antígenos antes da etapa de imunização. A fase de imunização tem início com a inoculação das soluções antigênicas nos animais, organizadas em períodos correspondentes aos tempos de resposta do sistema imunológico do equino a cada antígeno específico administrado. Após as fases de interação antígenos e sistema imune é realizada uma sangria exploratória, com objetivo de avaliar os níveis de anticorpos produzidos, e finalmente a sangria de produção, para obtenção do sangue do qual se extrai o soro especificamente hiperimunizado (Parra et al., 2009).

Além de obedecer à cadeia produtiva dos soros, a atividade exige outros cuidados com os animais, especialmente em relação ao manejo e a nutrição. Falhas nesses quesitos podem gerar problemas tanto à produção dos soros quanto aos equinos utilizados, predispondo-os a enfermidades. Devido à alta e frequente exposição imunogênica que ocorre nos animais há possibilidade do surgimento em alguns órgãos e especialmente no fígado de amiloidose, do grego amulon: amilo ou semelhante ao amido, descrita pela primeira vez por Virchow (Annes et al., 1997). Essa denominação foi empregada devido à semelhança entre o aspecto da pigmentação patológica sobre o órgão afetado e a forma física do amido, persistindo a nomenclatura até os dias atuais, designando um grupo de enfermidades raras e caracterizadas pela deposição extracelular de cadeias de origem proteicas fibrilares (Martinez et al., 2013).
Dentro da formação da amiloidose são possíveis três formas da doença, a amiloidose primária (De La Calle et al., 2016), considerada mais rara, e que pode ser isolada ou associada à doença linfoide clonal em humanos. A forma secundária, considerada reativa ou adquirida, normalmente oriunda de infecções agravadas ou inflamações crônicas que promovem a produção de proteínas reativas de fase aguda pelo fígado, a qual se identifica com os quadros nos equinos soroprodutores. E ainda a formação de amiloidose por origem hereditária, como referenciado por Monteiro e Diz (2014).

Segundo Sonne et al. (2008), derivações de fontes proteicas geram os quadros de amiloidose, são elas, proteínas amiloides do tipo A, de cadeia leve (AL) e de cadeia pesada (AA), além das proteínas tipo A do soro (SAA). Essas proteínas SAA podem ser detectadas como as primeiras proteínas de fase aguda aumentadas em dosagens séricas de bezerros com pneumonia, pneumoenterite e enterite (Kabu et al., 2016), ou seja, são observados maiores níveis sanguíneos em resposta a inflamações agudas. A ocorrência dos quadros de amiloidose primária e por fatores hereditários, geralmente é relacionada ao tipo de proteína $\mathrm{AL}$ (cadeias leves), enquanto os quadros secundários estão correlacionados à deposição de amiloide do tipo AA e SAA e a inflamações crônicas, promovendo deposição amiloide principalmente em rins, fígado, baço, linfonodos e trato gastrointestinal, como demonstrado por Afonso et al. (2016) na espécie bovina.

Entre a amiloidose e a produção de soros hiperimunes em equinos pode haver uma relação patológica ímpar, que normalmente não gera sinais clínicos evidentes enquanto os depósitos proteicos não causam danos mais graves e extensos, principalmente nas células do fígado, rins e baço. Esse curso agravado pode promover colestase em outras espécies, e normalmente leva o paciente a morte (Gavilán et al., 2003). A ausência de sinais clínicos específicos também é recorrente nos casos de amiloidose em humanos (López et al., 1999). Considerando essa particularidade, e devido à alta estimulação antigênica que promove maior demanda e produção de proteínas para resposta imunogênica, destaca-se os processos patológicos dessa natureza no fígado. O presente trabalho busca descrever através do relato de caso essa relação dentro do nicho de produção de soros hiperimunes utilizando a espécie equina, discorrendo sobre os meios de desenvolvimento da doença, relação de 
diagnóstico e sinais clínicos, e medidas básicas possíveis de serem adotadas para manutenção da saúde e do bem-estar desses animais.

\section{Descrição do Caso}

O presente relato ocorreu em uma propriedade rural produtora de soros localizada no norte do Paraná. Na fazenda eram utilizados aproximadamente 150 equinos (Equus caballos), predominantemente da raça Quarto de Milha e seus cruzamentos, e idades variadas. No processo de produção, eram utilizados antígenos comerciais, seguindo-se um padrão subsequente de inoculação, tempo de resposta, sangria exploratória, sangria produtiva, plasmaferese e período de recuperação adequada a cada tipo de soro produzido no referente animal.

O caso de amiloidose ocorreu no início do ano de 2017, em um único animal já encontrado em óbito sem a observação de sinais clínicos prévios, concluindo o diagnóstico somente por meio da análise necroscópica e histopatológica. A avaliação post mortem do equino indicou externamente um leve aumento de volume abdominal, mucosas porcelanizadas e temperatura corporal de $36,6^{\circ} \mathrm{C}$, evidenciando um óbito recente e com menores probabilidades de alterações morfofisiológicas post mortem que pudessem prejudicar a exatidão do diagnóstico necroscópico. À abertura do cadáver evidenciou-se edema generalizado de tecido subcutâneo ou anasarca, grande volume de líquido serossanguinolento no abdômen, não mensurado em quantidade no momento do exame. Pôde-se observar esplenomegalia e hepatomegalia, hemorragias e ruptura hepática nas regiões centrais de todos os lobos esquerdos do órgão e consistência friável, se desfazendo à manipulação simples durante o exame necroscópico. As alterações morfológicas citadas podem ser observadas na Figura 1.

Durante a necropsia foram coletados fragmentos do lobo medial esquerdo e do lobo lateral direito do fígado, além de um fragmento do baço, fixados em formol 10\%. O material foi enviado ao Laboratório Campos - Imagens e Diagnósticos Veterinários (Londrina-PR) para análise histopatológica. Na Figura 2 são apresentadas as imagens histológicas do fígado, onde foi observada a deposição de substância amorfa pericelular semelhante à deposição proteica, característica da amiloidose. Para confirmação foi empregada a coloração de Vermelho Congo, à qual apresenta afinidade pela deposição de amiloide secundário, se mostrando, portanto, compatível ao diagnóstico de amiloidose. O laudo de histopatologia também indicou processo hemorrágico generalizado no baço.

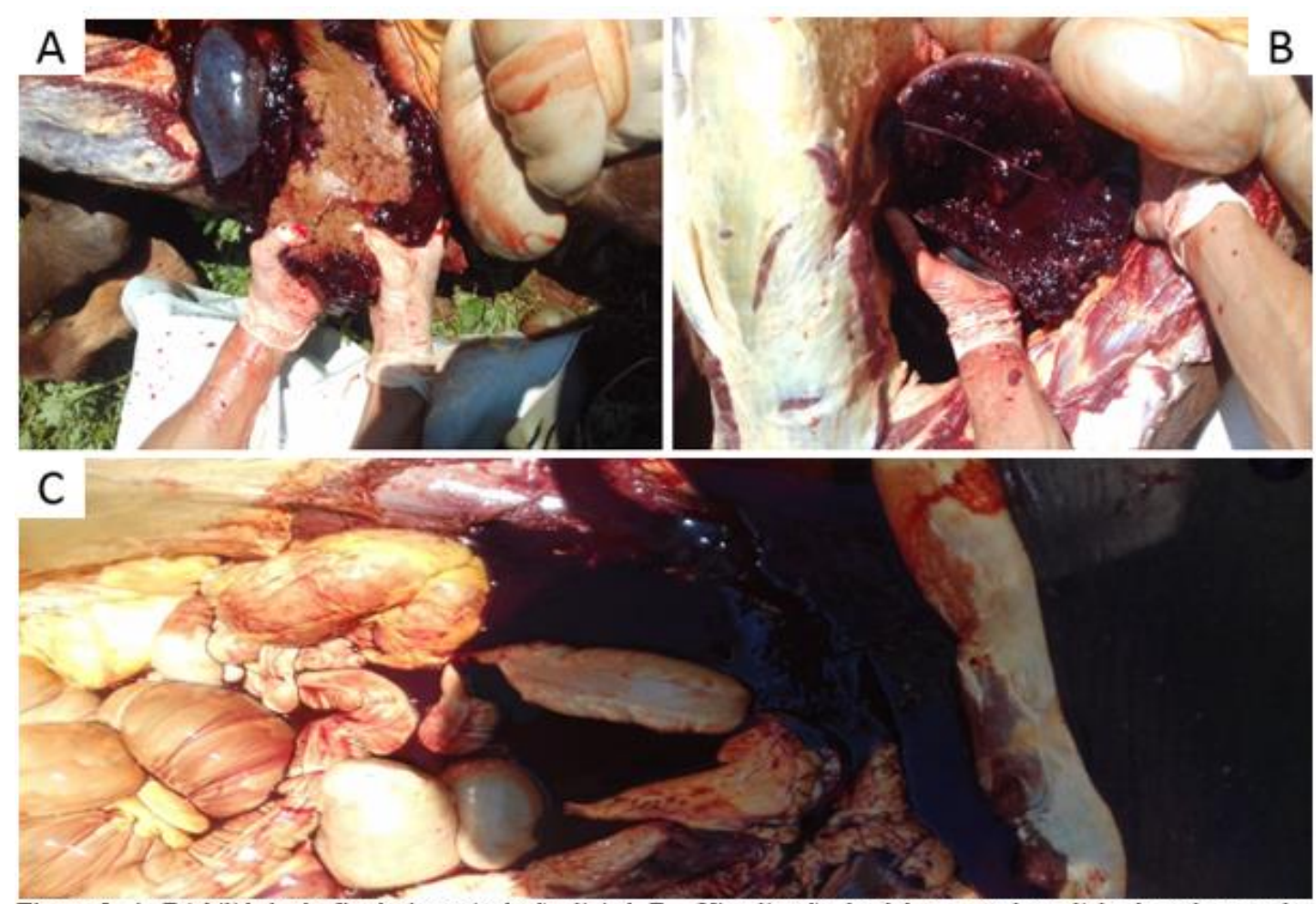

Figura 1. A. Friabilidade do figado à manipulação digital. B - Visualização dos lobos central, medial e lateral esquerdos rompidos e da hemorragia hepática. C - Líquido sanguinolento solto na cavidade abdominal. 


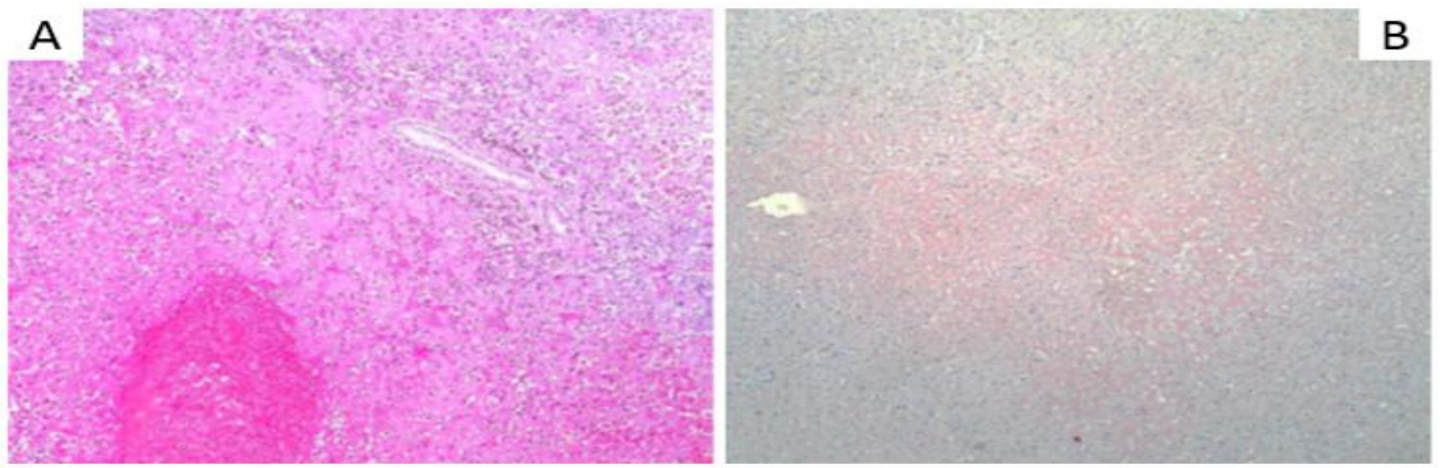

Figura 2. A. Avaliação microscópica de fragmento de figado. Observa-se ao longo dos espaços perissinusoidais e ao redor dos vasos dos tratos portais uma deposição acentuada e difusa de material amorfo eosinofilico opaco (sugestivo de material amiloide). Há vacuolização hepatocelular difusa e acentuada, áreas multifocais a focalmente extensas de necrose de coagulação e hemorragia acentuada, focalmente extensa à coalescente. B Cortes para coloração especial com vermelho congo, que evidenciou a deposição de material amiloide depositado na túnica média dos vasos e no espaço de Disse. O teste foi realizado sobre lâmina de vidro com microcortes do material biológico envolto por parafina, sendo o corante depositado acima do corte seriado de tecido. Na presença de material amiloide há conjugação ao complexo químico do corante vermelho congo que quando exposto ao exame com luz polarizada observa-se a alteração para a coloração determinada de verdemaçã.

A avaliação geral do rebanho não indicou problemas clínicos, apesar do elevado número de animais obesos dentro da linha de produção, com mais de $75 \%$ dos equinos da tropa com Escore de Condição Corporal (ECC) entre 7 e 9, na escala desenvolvida por Henneke et al. (1983). A dieta fornecida aos equinos não apresentava padronização, controle ou avaliação quanto à composição e eficiência, chegando a índices superiores à 20\% de Proteína Bruta (PB) dentro da dieta total. Ainda foram detectados níveis de fibras indigestíveis e de baixa digestibilidade acima de $33 \%$, principalmente em pastagens envelhecidas e sem manejo correto de altura e proporção de folhas/talos.

Após a confirmação do diagnóstico de amiloidose pela análise laboratorial das amostras retiradas durante a necropsia, houve preocupação com o estado fisiológico e metabólico de todo o restante da tropa. Apesar da ausência de doenças e problemas sanitários na tropa, havia baixa produtividade em litros de sangue e em aproveitamento do soro, e a condição corporal indicava quadros de obesidade. Esses fatores somados a perda de um indivíduo por doença metabólica, levaram a alterações no manejo geral da propriedade. A dieta foi corrigida, as pastagens foram reformadas e houve mudança na ração concentrada fornecida e no valor calórico da dieta total. Os índices de condição corporal foram controlados junto com adoção de medidas de equilíbrio do peso corporal de cada equino da propriedade. Tais manobras permitiram maior controle zootécnico sobre os animais e incremento da produção geral da propriedade, mantendo um estado de higidez tanto na aparência física quanto na fisiologia dos cavalos da tropa.

\section{Discussão}

Assim como no caso apresentado, a ocorrência de sinais clínicos é rara de acordo com a literatura disponível, sendo descritos poucos casos com características brandas e inespecíficas. Tanto em humanos quanto nos animais domésticos os quadros de amiloidose podem cursar com inapetência, perda de peso e diminuição de produção e rendimento, de acordo com Afonso et al. (2016), o qual também relataram diarreia aquosa e fétida. Já Alcatrão et al. (2016), relataram um quadro humano cursando com icterícia, hepatomegalia e aumento do volume abdominal, semelhante às alterações encontradas nesse estudo. Ainda, sinais de fraqueza muscular, icterícia e aumento de volume abdominal, foram citados por Queiroga et al. (2012), destacando o acometimento hepático recorrente nos quadros de amiloidose, gerando possíveis agravamentos relacionados à lesões de maior evolução e provável acometimento sistêmico, havendo risco eminente de óbito.

Apesar da inocorrência de problemas clínicos e aspecto de higidez dos animais da propriedade, os índices de volume de soro produzido e capacidade de volume de sangue colhido na sangria final apresentavam-se reduzidos frente ao potencial da propriedade. Assim sendo, pela necropsia após o óbito do animal, foi detectada a ocorrência da amiloidose, que pode ter causa relacionada a estimulação antigênica aumentada pelo tipo de atividade e o fornecimento de dieta inapropriada. Avaliando a obesidade em mais de $75 \%$ dos animais, a contenção dos índices produtivos, o consumo de forrageiras fibrosas e a dieta inadequada, suspeitou-se da ocorrência de quadros assintomáticos ou com baixa repercussão sistêmica, podendo concorrer com pequenas lesões 
hepáticas geradas pela deposição das substâncias amiloides, interferindo na função hepática, homeostase, equilíbrio metabólico e rendimento produtivo. Tais adversidades poderiam ser causas de resultados de produção inferiores e de possíveis problemas futuros, exigindo a readequação do manejo e da dieta dos animais.

Mesmo nos casos de lesões hepáticas os sinais clínicos também estão previamente ausentes, porém podem ser avaliadas algumas alterações enzimáticas e bioquímicas indicativas de problemas na função hepática. A patogenia dessas afecções é complexa, portanto os níveis séricos aumentados das enzimas AST (Aspartato Amino Transferase) na avaliação da lesão direta aos hepatócitos, e da GGT (Gama Glutamil Transferase) em quadros de colestase, são de fundamental auxilio ao diagnóstico (Franciscato et al., 2006). Também pode ser avaliada a bioquímica sérica relacionada ao fígado, como a albumina, que normalmente tem baixa alteração em equinos, fatores II, V, VII e X de coagulação, fibrinogênio, bilirrubina, ureia e amônia. Esses produtos geralmente apresentam-se alterados quando mais de $60 \%$ do órgão encontra-se acometido (Gomes et al., 2008).

Diante desse quadro de difícil identificação, normalmente o diagnóstico da amiloidose nos equinos é realizado pelos exames de necropsia e histopatologia, ou seja, após o óbito evidente com a evolução rápida dos quadros que chegam à níveis sistêmicos. Portanto, para evitar a perda e manter a homeostase e a higidez desses animais, podem ser adotadas algumas medidas relacionadas à arraçoamento, nutrição, avaliações clínica e laboratorial periódicas e emprego de técnicas e manejos que auxiliem na recuperação e manutenção da saúde dos animais na linha de produção.

As grandes necessidades metabólica e hepática empregadas à esses animais exigem balanço correto e direcionamento da dieta voltado às particularidades dos equinos soroprodutores. Betiol et al. (2008) avaliaram uma alimentação hiperproteica para equinos soroprodutores, não encontrando interferências dos teores de proteína bruta na produção de colesterol e triglicerídeos, sugerindo uma possível maior influência da origem e qualidade dos alimentos. Após a detecção dos problemas relacionados à amiloidose alguns manejos com o rebanho foram alterados, iniciando pela dieta e adequação dos pesos e do escore corporal, evitando os extremos e mantendo os cavalos em escore entre 4,5 e 6,5 e entre 300 e 500 $\mathrm{kg}$. Com a dieta mais adequada, melhores fontes de pastagens e rações balanceadas, além do controle dos índices corporais, pode ser observada a elevação na produção de anticorpos por $\mathrm{mL}$ de soro coletado, ou seja, a qualidade da dieta pode ser um dos fatores à refletir na resposta imune $\mathrm{e}$ consequentemente na produção de anticorpos.

Outras pesquisas relacionadas ao manejo de soroprodutores indicam uma redução drástica do hematócrito após a sangria de produção, havendo inclusive a possibilidade de insuficiência eritrocitária. Como manobra para contornar essa dificuldade surge a plasmaferese, que segundo Parra et al. (2009) auxilia em uma recuperação parcial e rápida do cavalo. $\mathrm{O}$ método consiste em obter as hemácias após a extração do soro oriundo da sangria produtora, administrando esse conteúdo celular por via intravenosa novamente no mesmo equino doador.

Além da nutrição adequada e do emprego da plamaférese é importante respeitar os tempos de recuperação entre os períodos de produção dos soros. Os métodos citados e utilizados atualmente na propriedade auxiliam em maior higidez dos cavalos após as sangrias de produção, porém não substituem a recuperação natural do organismo frente aos desafios imunogênicos das inoculações de antígenos e a perda sanguínea temporária causada pelas sangrias. Deve-se manter constante avaliação clínica e laboratorial, visando saúde individual e coletiva do rebanho, bem-estar e controle produtivo, sempre respeitando os limites e exigências fisiológicas da espécie e de cada animal utilizados para esse fim. A adoção das medidas descritas não elimina o risco de amiloidose e de outras doenças ligadas a produção de soros, porém permitem controle e conhecimento prévio de problemas iminentes e as vezes silenciosos, além de vislumbrar melhores índices produtivos e melhor qualidade de vida aos doadores.

\section{Conclusão}

A ocorrência de quadros de amiloidose é rara, porém as características de evolução gradativa e silenciosa ao óbito, impossibilidade de tratamento e ausência de manifestação clínica evidente antes do risco eminente de morte, exigem melhor monitoramento dos animais soroprodutores. Os cuidados de manejo, arraçoamento e nutrição são fundamentais, tanto para manutenção da saúde, higidez e bem-estar dos equinos quanto para os índices de produção de soro 
e anticorpos. Os protocolos de descanso entre etapas produtivas são essenciais no bom desenvolvimento da atividade, e manejos como a plasmaferese surgem como alternativa para auxiliar nesses períodos.

\section{Conflitos de Interesse}

Os autores declaram não haver conflitos de interesse.

\section{Comitê de ética}

Não há protocolo deferido pelo Comitê de Ética, o estudo do caso surgiu à partir de um atendimento médico veterinário à propriedade de produção de soros, portanto não utilizou-se de experimentação com animais para os devidos fins do presente artigo científico.

\section{Referências}

Afonso, J.A.B.; Silva, R.J.; Amorim, R.L.; Coutinho, L. T.; Mendonça, C. L.; Souza, J.C.A. Amiloidose em bovinos: Relato de casos. Ciência Veterinária nos Trópicos, 19(1): 4046, 2016.

Alcatrão, M.J.; Neves, C.; Gaspar, A.; Bravo, A.; Margarido, E.; Estrada, H. Mieloma múltiplo e amiloidose AL. Revista da Sociedade Portuguesa de Medicina Interna, 23(1): 2831, 2016.

Annes, M.; Oliveira, A.N.B.; Oliveira, E.M.L.; Gabbai, A.A. Amiloidose. Revista Neurociências, 5(1): 07-13, 1997.

Betiol, P.S.; Távora, J.P.F.; Parra, A.C.; Sucupira, M.C.A.; Gregory, L. Determinação sérica de colesterol e triglicérides em cavalos soroprodutores alimentados com concentrados com teores de $15 \%$ ou $22 \%$ de proteína bruta. Brazilian Journal of Veterinary Research and Animal Science, 45(supl.): 20-26, 2008.

Brasil, V. Soros/Instituto Butantan. Butantã, Governo do Estado de São Paulo. Disponível em:

$<$ http://www.butantan.gov.br/producao/soros/P aginas/default.aspx>. Acesso em: 24 de ago. 2017.

De La Calle, V.G.; García-Sanz, R.; Mateos, M.V. Primary amyloidosis. Medicina Clínica (Barcelona), 147(3): 121-126, 2016.

Franciscato, C.; Lopes, S.T.A.; Veiga, Â.P.M.; Martins, D.B.; Emanuelli, M.P.; Oliveira, L.S.S. Atividade sérica das enzimas AST, CK e GGT em cavalos crioulos. Pesquisa Agropecuária Brasileira, 41(10): 1561-1565, 2006.
Gavilán, J.C.; Bermúdez, F.J.; Márquez, A.; SánchezCarrillo, J.J.; González-Santos, P. Amiloidosis hepática como causa de colestasis severa intra hepática. Anales de Medicina Interna (Madrid), 20(1): 25-27, 2003.

Gomes, A.; Parra, B.S.; Franco, F.O.; Basile, L.; Jose, L.T.; Romero, V.L.; Sacco, S.R. Exame da função hepática na Medicina Veterinária. Revista Científica Eletrônica de Medicina Veterinária, 11(2): 1-7, 2008.

Henneke; D.R.; Potter, G.D.; Kreider, J.L.; Yeatles, B.F. Relationship between condition score, physical measurements and body fat percentage in mares. Equine Veterinary Journal, 15(4): 371-372, 1983

Kabu, M.; Elitok, B.; Kucukkurt, I. Detection of serum amyloid A concentration in the calf clinically diagnosed with pneumonia, enteritis and pneumoenteritis. Ciência Rural, 46(2): 293-299, 2016.

López, M.F.; Valdez, Y.G.; Hernández, P.J.; Delgado, W.; López, M.H.V.; Santayana, N.; Silva, D.H. Amiloidosis secundaria. Características clínicas. Revista Médica Herediana, 10(2): 45-48, 1999.

Martínez, G.A.; Tolosa, R.G.; Bonfanti, A.C.; Taboada, M.A.; Niño, L.M.; Bautista, E.C.; Ruiz, E.H. Amiloidosis renal: reporte de un caso y revisión de tema renal amyloidosis: case report and review. Ciência e Innovación em Salud, 1(2): 134-142, 2013.

Monteiro, N.F.; Diz, M.C.E. Dificuldades no diagnóstico da amiloidose primária: Relato de caso. Revista Médica de Minas Gerais, 25(2): 280-286, 2015.

Parra, A.C.; Távora, J.P.F.; Ferreira, R.A.; Betiol, P.S.; Birgel, E.H. Alterações hematológicas durante a imunização e após a sangria e plamaférese em equinos de produção de soro hiperimune anticrotalárico. Ciência Rural, 10(4): 1225-1230, 2009.

Queiroga, V.M.B.; Macedo, M.R.F.; Rolim, T.M.L.; Pessoa, F.S.R.P.; Meneses, D.B. Insuficiência hepática grave associada à amiloidose hepática: Relato de caso. Revista da Sociedade Brasileira de Endoscopia Digestiva, 31(1): 2933, 2012.

Sonne, L.; Oliveira, E.C.; Santos, A.S.; Pavarini, S.P.; Junior, P.S.B.; Antoniassi, M.A. B.; Tessari, J.P.; Driemeier, D. Amiloide sistêmica do tipo AA em um canino Shar-pei chinês. Acta Scientiae Veterinary, 36(1): 47-50, 2008. 